\title{
EFFECTS OF LIGHT CONDITIONS AT DIFFERENT GROWTH STAGES ON GROWTH AND PHOTOSYNTHETIC CHARACTERISTICS OF PINUS SYLVESTRIS VAR. SYLVESTRIFORMIS SEEDINGS
}

\author{
JIN, H. - QIN, L. W. - LIU, L. J. - CHEN, Q. H. - JIA, X. - DAI, Y. H. - ZHAO, Y. * YIN, H. \\ Jilin Provincial Joint Key Laboratory of Changbai Mountain Biocoenosis and Biodiversity, \\ Changbai Mountain Academy of Sciences, Antu 133613, P. R. China \\ *Corresponding authors \\ e-mail: rjrge26m@163.com; fivecl10jinhui@163.com
}

(Received $14^{\text {th }}$ Sep 2020; accepted $18^{\text {th }}$ Dec 2020)

\begin{abstract}
Pinus sylvestris var. sylvestriformis is an endemic plant in Changbai Mountain area of China. Five different light levels were simulated and designed with control experiments: full sunlight (CK), light shading (light transmittance was 10\%) (LA), light and moderate shading (light transmittance was 20\%) (LB), moderate shading (light transmittance was 40\%) (LC), and severe shading (light transmittance was $60 \%$ ) (LD). The optimal light levels and the main physiological and ecological factors affecting photosynthesis in different growth stages were discussed. The results showed that the phenotypic index and photosynthetic physiological and ecological indicators were the highest when the light transmittance was $40 \%$. In the early growth phase, the physiological factors intercellular $\mathrm{CO}_{2}$ concentration $\left(C_{i}\right)$ and ecological factors transmittance (Tran) and air temperature (Temp) jointly affected the changes of net photosynthetic rate $\left(P_{n}\right)$. In the peak growth phase, transpiration rate $\left(T_{r}\right)$, air humidity $(R H)$, and Tran had greater direct positive effects on $P_{n}$, and $C_{i}$ and stomatal conductance $\left(G_{s}\right)$ had direct negative effects on $P_{n}$. In the later growth phase, $T_{r}$ and $C_{i}$ had large direct positive effects on $P_{n}$. The research results could provide important references for the scientific cultivation and popularization of $P$. sylvestris var. sylvestriformis.

Keywords: P. sylvestris var. sylvestriformis, light transmittance, growth phases, the phenotypic index, photosynthetic physiological and ecological indicators
\end{abstract}

\section{Introduction}

Light is an important environmental factor that affects the growth and development, morphogenesis, regeneration, and distribution of plants (Rozendaal et al., 2006). Plants regulate their growth and development by sensing the changes of light signals in the external environment (Kim et al., 2017). In the weak light environment, the plant's ability to capture light is limited, which restricts the photosynthetic capacity of plants and causes the decrease of photosynthetic rate, but it will increase the content of photosynthetic pigment to increase the ability to capture light energy (Liu et al., 2011). "Trade- off theory" holds that under shading conditions, plants tend to allocate more biomass to the aboveground part and less to the root, which affects water absorption (Smith et al., 1989). In order to cope with different light conditions, plants can increase the utilization of light energy through morphological and physiological plasticity response, so as to avoid the photoinhibition or photodamage, and finally reduce the photosynthetic rate (Duan et al., 2005).

Pinus sylvestris var. sylvestriformis is a rare and endangered tree species in Changbai Mountain, China's national first-class protected plant. The natural population of $P$. sylvestris var. sylvestriformis is distributed in the northern slope of Changbai Mountain and Changbai Mountain Nature Reserve in China, with a small area of about $200 \mathrm{hm}^{2}$. 
Because of its straight trunk, beautiful tree shape, and handsome posture, the local people called it "beauty pine." However, in recent years, due to the increase of population, economic development, and environmental damage, the number of $P$. sylvestris var. sylvestriformis has become less and less, which has reached the edge of extinction and needs further protection (Bu et al., 1995).

There is a strong correlation between plant growth and light environment heterogeneity, especially light intensity (Bazzaz, 1996). The need and sensitivity of seedlings growth to light are high, so it is often necessary to adopt necessary tending measures according to the response of seedlings to light (Welander and Ottosson, 1998; Wang, 2008). In order to obtain the best light environment for the growth of $P$. sylvestris var. sylvestriformis seedlings, so as to take corresponding tending measures, it is particularly important to study and practice the response of $P$. sylvestris var. sylvestriformis seedlings to the light environment.

At present, researches on $P$. sylvestris var. sylvestriformis mainly involve the population, community and ecological investigation, etc. (Hu et al., 1966; Zhao et al., 2002; Zhao et al., 2017; Jin et al., 2015; Chen et al., 2017). It is not reported to study the growth status of $P$. sylvestris var. sylvestriformis and analyze the dynamic changes of leaf photosynthesis in the whole growth period by short- term artificial control of light conditions.

In this experiment, through artificial shading treatment, the growth status and photosynthetic parameters of $P$. sylvestris var. sylvestriformis seedlings under different light conditions at different growth stages were observed continuously. The adaptability of $P$. sylvestris var. sylvestriformis seedlings to different light conditions was discussed, and the effects of environmental factors on Photosynthesis in different growth phases were analyzed. In order to seek the most suitable light conditions to promote the growth of $P$. sylvestris var. sylvestriformis seedlings, and to identify the main physiological and ecological factors that affect the photosynthesis of $P$. sylvestris var. sylvestriformis in different growth phases. So as to provide theoretical basis and technical reference for scientific management of $P$. sylvestris var. sylvestriformis seedlings.

\section{Materials and methods}

\section{Overview of experimental sites}

The experimental site is located at Northeast Asia Arboretum of Changbai Mountain Nature Reserve, China, with a geographical location of $128^{\circ} 01^{\prime} \mathrm{E}, 42^{\circ} 22^{\prime} \mathrm{N}$, and the altitude of $770-780 \mathrm{~m}$, the climate belongs to the temperate continental monsoon alpine climate. The annual average temperature is $3-7{ }^{\circ} \mathrm{C}$. The minimum temperature has appeared $-44^{\circ} \mathrm{C}$. The annual sunshine hours are less than 2300 hours. The frost-free period is about 100 days. The annual precipitation is between $700-1400 \mathrm{~mm}$, and $6-9$ month accounts for $60-70 \%$ (Yin et al., 2017).

\section{Test materials and methods}

\section{Materials}

Biennial seedlings were planted in the spring of 2016 in the test site, and the test was conducted in May 2018. The shading nets with a light transmittance of $10 \%, 20 \%, 40 \%$, and $60 \%$ were selected. 


\section{Cultivation substrate}

The ratio of dark brown loam to river sand was $2: 1$. When cultivated, the border was $35 \mathrm{~cm}$ high and $120 \mathrm{~cm}$ wide.

\section{Experimental methods}

There were five treatments in the light environment:

CK control: full sunlight;

LA: light transmittance was $10 \%$;

LB: light transmittance was $20 \%$;

LC: light transmittance was $40 \%$;

LD: light transmittance was $60 \%$.

During the experiment, the maximum light intensity of each treatment was monitored by HOBOU12 environmental factor monitor of American HOBO Onset Company at noon on five sunny days. The light intensity is as follows:

CK control: 112304-128032 lux;

LA: 3313-7594 lux;

LB: 13656-28546 lux;

LC: 45644-69650 lux;

LD: 58762-79364 lux.

Each sunshade was $6 \mathrm{~m}$ long, $4 \mathrm{~m}$ wide and $2 \mathrm{~m}$ high. Each treatment was repeated three times, with 20 plants per repeat. The plant row spacing was $20 \mathrm{~cm}$ by $20 \mathrm{~cm}$. The seedling height, ground diameter, and leaf length (maximum leaf length) of $P$. sylvestris var. sylvestriformis seedlings were measured in June, July, August, and September, respectively. From May to October, a sunny day was choosing every month, photosynthetic characteristics were measured using an LI- 6400 portable photosynthesis system (American LI- COR Company) between 9 a.m. and 11 a.m. The effective light radiation was set at 1500 lux. The net photosynthetic rate $\left(P_{n}\right)$, stomatal conductance $\left(G_{s}\right)$, transpiration rate $\left(T_{r}\right)$, and intercellular $\mathrm{CO}_{2}$ concentration $\left(C_{i}\right)$ of $P$. sylvestris var. sylvestriformis seedlings of different treatments were measured. Each repeating was measured once, and the data acquisition time was 3 minutes, which would be recorded after it was stable.

During the period from mid-May to October 2019, the HOBOpro automatic temperature and humidity recorder was used to automatically collect the atmospheric temperature and relative humidity during the test period every half an hour.

\section{Data processing and analysis}

All data were analyzed by Excel and IBM SPSS statistics software for multiple comparison, significance test, regression analysis, simple correlation analysis and path analysis. The statistical graph was drawn by sigmaplot 14.0. Descriptive statistics were expressed in mean \pm SEM and letter notation.

\section{Results and analysis}

\section{Changes in temperature and relative humidity}

Figure 1 showed course of daily and monthly average temperature and relative humidity in experimental period. The temperature of the experimental area was low in May, with an average monthly temperature of $15.71^{\circ} \mathrm{C}$, an average monthly relative 
humidity of $63.95 \%$, and the air was dry. From June to August, the temperature rose rapidly. From July to August, the temperature reached its highest value. This period was the main rainfall period. The temperature difference between day and night was large. The monthly average temperature was $20.43{ }^{\circ} \mathrm{C}$ and $19.36^{\circ} \mathrm{C}$, respectively. The weather was humid and cool. From September to October, the temperature gradually decreased, with the lowest temperature in October. The monthly average temperature was below $10{ }^{\circ} \mathrm{C}$. The monthly average relative humidity of the air was maintained at about $66 \%$. The weather was dry and cold.
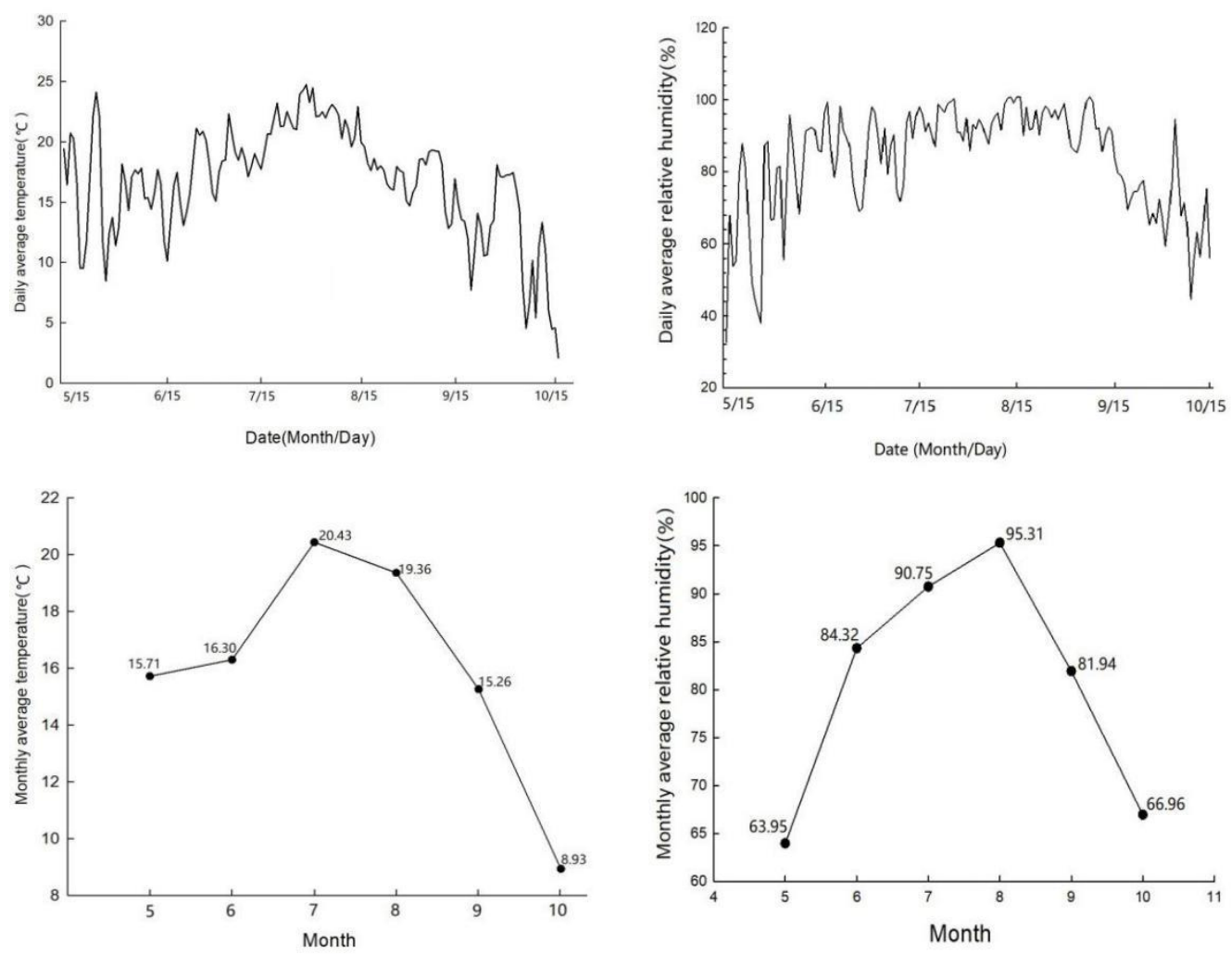

Figure 1. Course of daily and monthly average temperature and relative humidity in experimental period

\section{Effects of different light conditions on the growth of $P$. sylvestris var. sylvestriformis seedlings}

Effects of different light conditions on plant height of P. sylvestris var. sylvestriformis seedlings

Table 1 showed the average plant height of each treatment measured in different months. According to the plant height of two adjacent months, the change rate of plant height of different treatments in each month is further calculated. From June to July, plant height change rate of treatment $\mathrm{CK}$ was $39.48 \%$, plant height change rate of treatment LA was $14.22 \%$, plant height change rate of treatment LB was $24.46 \%$, plant height change rate of treatment LC was $37.65 \%$, plant height change rate of treatment LD was $42.44 \%$. Based on the change rate of plant height treated with treatment $\mathrm{CK}$, the plant height of P. sylvestris var. sylvestriformis seedlings decreased by $25.26 \%$ after treatment LA, 
$15.02 \%$ after treatment $\mathrm{LB}, 1.83 \%$ after treatment $\mathrm{LC}$ than treatment $\mathrm{CK}$, but after treatment LD, the plant height increased by $2.96 \%$ than CK. From July to August, based on the change rate of plant height treated with $\mathrm{CK}$, after each treatment, the height of seedlings increased by $4.46 \%, 4.76 \%, 19.39 \%$, and $16.70 \%$, respectively, compared with that of treatment CK (full sunlight). From August to September, based on the change rate of plant height treated with CK, the height of seedlings increased by $0.71 \%, 2.15 \%$, $3.45 \%$, and $1.43 \%$ compared with that of treatment CK.

Table 1. Growth of plant height in different months (cm)

\begin{tabular}{c|c|c|c|c}
\hline Tran & June & July & August & September \\
\hline CK & $12.21 \pm 2.74 \mathrm{a}$ & $17.03 \pm 2.38 \mathrm{ab}$ & $19.04 \pm 3.02 \mathrm{ab}$ & $19.42 \pm 3.24 \mathrm{bc}$ \\
LA & $13.08 \pm 1.17 \mathrm{a}$ & $14.94 \pm 1.69 \mathrm{~b}$ & $17.37 \pm 1.91 \mathrm{~b}$ & $17.84 \pm 1.75 \mathrm{c}$ \\
LB & $14.31 \pm 1.34 \mathrm{a}$ & $17.81 \pm 1.31 \mathrm{a}$ & $20.76 \pm 0.74 \mathrm{a}$ & $21.62 \pm 0.29 \mathrm{ab}$ \\
LC & $11.9 \pm 0.06 \mathrm{ab}$ & $16.38 \pm 0.15 \mathrm{ab}$ & $21.49 \pm 1.08 \mathrm{a}$ & $22.66 \pm 1.13 \mathrm{a}$ \\
LD & $9.26 \pm 0.98 \mathrm{~b}$ & $13.19 \pm 0.38 \mathrm{c}$ & $16.95 \pm 0.59 \mathrm{~b}$ & $17.53 \pm 0.63 \mathrm{c}$ \\
\hline
\end{tabular}

Note: Lowercase letters in the same column represented significance differences at the $p<0.05$ level

The growth rates of plant height of $P$. sylvestris var. sylvestriformis seedlings treated by CK, LA, LB, LC and LD from June to September were 59.05\%, 36.39\%, 51.08\%, $90.42 \%$, and $89.31 \%$, respectively. The growth rate during the growing season was as follows: treatment LC> LD> CK> LD> LA. The plant height of each treatment showed an upward trend during the whole growing season. The plant height of treatment CK, LB, LC, LD increased rapidly in the period of June-July. The plant height of treatment LA increased rapidly in the period of July- August. Each treatment increased slowly in the period of August- September.

Effects of different light conditions on the ground diameter of P. sylvestris var. sylvestriformis seedlings

Table 2 showed the average ground diameter of each treatment measured in different months. According to the ground diameter of two adjacent months, the change rate of the ground diameter of different treatments in each month is further calculated. From June to July, the ground diameter change rate of treatment CK was $19.25 \%$, the ground diameter change rate of treatment LA was 5.57\%, the ground diameter change rate of treatment LB was $15.49 \%$, the ground diameter change rate of treatment LC was $21.49 \%$, the ground diameter change rate of treatment LD was $7.34 \%$. Based on the change rate of the ground diameter treated with treatment $\mathrm{CK}$. the ground diameter of $P$. sylvestris var. sylvestriformis seedlings decreased by $13.68 \%$ after treatment LA, 3.76\% after treatment LB, $11.91 \%$ after treatment LD than treatment CK, but after treatment LC, the ground diameter increased by $2.24 \%$ than treatment CK. From July to August, based on the change rate of the ground diameter treated with $\mathrm{CK}$, the ground diameter of $P$. sylvestris var. sylvestriformis seedlings decreased by $9.14 \%$ after treatment LA, $4.53 \%$ after treatment LB, $0.04 \%$ after treatment LC than treatment CK, but after treatment LD, the ground diameter increased by $0.93 \%$ than CK. From August to September, the ground diameter seedlings decreased by $1.34 \%$ after treatment LA, $0.83 \%$ after treatment LB, $0.72 \%$ after treatment LC, $3.68 \%$ after treatment LD than treatment CK. 
Table 2. Growth of ground diameter in different months $(\mathrm{mm})$

\begin{tabular}{c|c|c|c|c}
\hline Tran & June & July & August & September \\
\hline CK & $3.22 \pm 0.56 \mathrm{a}$ & $3.84 \pm 0.67 \mathrm{ab}$ & $4.37 \pm 0.59 \mathrm{a}$ & $4.48 \pm 0.08 \mathrm{~b}$ \\
LA & $3.05 \pm 0.34 \mathrm{a}$ & $3.22 \pm 0.34 \mathrm{~b}$ & $3.37 \pm 0.35 \mathrm{~b}$ & $3.50 \pm 0.37 \mathrm{a}$ \\
LB & $3.55 \pm 0.06 \mathrm{a}$ & $4.10 \pm 0.08 \mathrm{a}$ & $4.48 \pm 0.11 \mathrm{a}$ & $4.63 \pm 0.17 \mathrm{a}$ \\
LC & $3.35 \pm 0.12 \mathrm{a}$ & $4.07 \pm 0.12 \mathrm{ab}$ & $4.63 \pm 0.08 \mathrm{a}$ & $4.78 \pm 0.10 \mathrm{a}$ \\
LD & $3.54 \pm 0.17 \mathrm{a}$ & $3.80 \pm 0.28 \mathrm{ab}$ & $4.36 \pm 0.33 \mathrm{~b}$ & $4.63 \pm 0.47 \mathrm{a}$ \\
\hline
\end{tabular}

Note: Lowercase letters in the same column represented significance differences at the $p<0.05$ level

The growth rates of the ground diameter of $P$. sylvestris var. sylvestriformis seedlings treated by CK, LA, LB, LC and LD from June to September were 39.13\%, 14.75\%, $30.42 \%, 42.69 \%$, and $30.79 \%$, respectively. The ground diameter of each treatment showed an upward trend during the whole growing season. The ground diameter of treatment CK, LB, LC, LD increased rapidly in the period of June- August and increased slowly in the period of August-September. The ground diameter of treatment LA increased slowly during the whole growing season.

Effects of different light conditions on the leaf length of P. sylvestris var. sylvestriformis seedlings

Table 3 showed the average leaf length of each treatment measured in different months. According to the leaf length of two adjacent months, the change rate of the leaf length of different treatments in each month is further calculated. From June to July, the leaf length change rate of treatment $\mathrm{CK}$ was $10.24 \%$, the leaf length change rate of treatment LA was $10.86 \%$, the leaf length change rate of treatment LB was $10.23 \%$, the leaf length change rate of treatment LC was $16.91 \%$, the leaf length change rate of treatment LD was $14.77 \%$. Based on the change rate of the leaf length treated with treatment CK. the leaf length of $P$. sylvestris var. sylvestriformis seedlings increased by $0.62 \%$ after treatment LA, $6.67 \%$ after treatment LC, $4.53 \%$ after treatment LD than treatment CK, but after treatment LB, the leaf length decreased by $0.01 \%$ than treatment CK. From July to August, the leaf length of seedlings decreased by $13.22 \%$ after treatment LA, $2.25 \%$ after treatment LD than treatment CK and the leaf length of seedlings increased by $0.69 \%$ after treatment LB, $7.70 \%$ after treatment LC than treatment CK. From August to September, the leaf length of seedlings increased by $3.56 \%$ after treatment LB, 3.90\% after treatment LC, $0.79 \%$ after treatment LD than treatment CK, but after treatment LA, the leaf length decreased by $0.45 \%$ than treatment CK.

Table 3. Growth of leaf length in different months (cm)

\begin{tabular}{c|c|c|c|c}
\hline Tran & June & July & August & September \\
\hline CK & $5.86 \pm 0.82 \mathrm{~b}$ & $6.46 \pm 0.70 \mathrm{c}$ & $8.06 \pm 0.92 \mathrm{bc}$ & $8.36 \pm 0.72 \mathrm{c}$ \\
LA & $6.17 \pm 0.09 \mathrm{ab}$ & $6.84 \pm 0.11 \mathrm{bc}$ & $7.63 \pm 0.48 \mathrm{c}$ & $7.88 \pm 0.33 \mathrm{c}$ \\
LB & $6.45 \pm 0.15 \mathrm{ab}$ & $7.11 \pm 0.12 \mathrm{abc}$ & $8.92 \pm 0.29 \mathrm{ab}$ & $9.57 \pm 0.07 \mathrm{~b}$ \\
LC & $6.27 \pm 0.11 \mathrm{ab}$ & $7.33 \pm 0.21 \mathrm{ab}$ & $9.71 \pm 0.84 \mathrm{a}$ & $10.45 \pm 0.13 \mathrm{a}$ \\
LD & $6.77 \pm 0.56 \mathrm{a}$ & $7.77 \pm 0.35 \mathrm{a}$ & $9.52 \pm 0.66 \mathrm{a}$ & $9.95 \pm 0.69 \mathrm{ab}$ \\
\hline
\end{tabular}

Note: Lowercase letters in the same column represented significance differences at the $p<0.05$ level 
The growth rates of leaf length of $P$. sylvestris var. sylvestriformis seedlings treated by CK, LA, LB, LC and LD from June to September were 42.66\%, 27.71\%, 48.37\%, $66.67 \%$, and $46.97 \%$, respectively. The leaf length of each treatment showed an upward trend during the whole growing season. The leaf length of treatment CK, LB, LC, LD increased rapidly in the period of July- August and increased slowly in the period of JuneJuly and August- September. The leaf length of treatment LA increased slowly during the whole growing season.

Growth distribution of $P$. sylvestris var. sylvestriformis seedlings under different light conditions

Table 4 showed that under the condition of treatment LC, the growth of ground diameter was $1.43 \mathrm{~mm}$, which was the highest under each treatment, and the difference from treatment CK was not significant. The growth of ground diameter was only $0.45 \mathrm{~mm}$ under treatment LA, which was the lowest under all treatments. The difference was significant compared with other treatments $(p<0.05)$.

Table 4. Growth distribution of P. sylvestris var. sylvestriformis seedlings under different light conditions

\begin{tabular}{c|c|c|c}
\hline Tran & Ground diameter $/ \mathbf{m m}$ & Plant height $/ \mathbf{c m}$ & Leaf length $/ \mathbf{c m}$ \\
\hline CK & $1.16 \pm 0.12 \mathrm{a}$ & $7.22 \pm 1.01 \mathrm{bc}$ & $2.50 \pm 0.18 \mathrm{bc}$ \\
LA & $0.45 \pm 0.03 \mathrm{~b}$ & $4.76 \pm 0.21 \mathrm{c}$ & $1.71 \pm 0.14 \mathrm{c}$ \\
LB & $1.09 \pm 0.11 \mathrm{a}$ & $7.31 \pm 1.23 \mathrm{bc}$ & $3.12 \pm 0.22 \mathrm{ab}$ \\
LC & $1.43 \pm 0.24 \mathrm{a}$ & $10.76 \pm 1.68 \mathrm{a}$ & $4.18 \pm 0.19 \mathrm{a}$ \\
LD & $1.08 \pm 0.09 \mathrm{a}$ & $8.28 \pm 0.75 \mathrm{ab}$ & $3.18 \pm 0.28 \mathrm{ab}$ \\
\hline
\end{tabular}

Note: Lowercase letters in the same column represented significance differences at the $p<0.05$ level

Under the condition of treatment LC, the growth of plant height was $10.76 \mathrm{~cm}$, which was the highest under each treatment, and the difference was significant $(p<0.05)$. The growth of plant height was only $4.76 \mathrm{~cm}$ under treatment LA, which was the lowest under all treatments, and the difference from treatment $\operatorname{LD}(p<0.05)$ was significant.

Under the condition of treatment LC, the growth of leaf length was $4.78 \mathrm{~cm}$, which was the highest under each treatment, and the difference from treatment $\mathrm{CK}(p<0.05)$ was significant. The growth of leaf length under treatment LA was $1.71 \mathrm{~cm}$, and the difference from treatment CK was not significant.

\section{Division of growth and development stages of P. sylvestris var. sylvestriformis}

After years of continuous observation of plant growth law in Changbai Mountain area, the growth period can be divided into three periods: 1. Early growth phase: from mid-May to the end of June, the plant growth is the fastest; 2 . The peak growth period: from the beginning of July to the end of August, the plant growth is slower than the initial growth; 3. The late growth period: from the beginning of September to mid-October, the growth is slow or even stopped. 


\section{Changes of leaf photosynthetic parameters in different growth phases}

Photosynthetic capacity of $P$. sylvestris var. sylvestriformis seedlings in different growth phases

It could be seen from Figure 2 that $P_{n}, G_{s}, C_{i}$ and $T_{r}$ of $P$. sylvestris var. sylvestriformis seedlings under different light conditions could be roughly divided into four stages of "low, rapid rise, stable and decline" in the whole growth phases. Combined with the growth law, growth period division and photosynthesis monitoring of $P$. sylvestris var. sylvestriformis seedlings, it was found that the growth and photosynthetic characteristics basically overlapped. Therefore, the seasonal variation of photosynthetic characteristics could accurately reflect the change of its growth cycle.
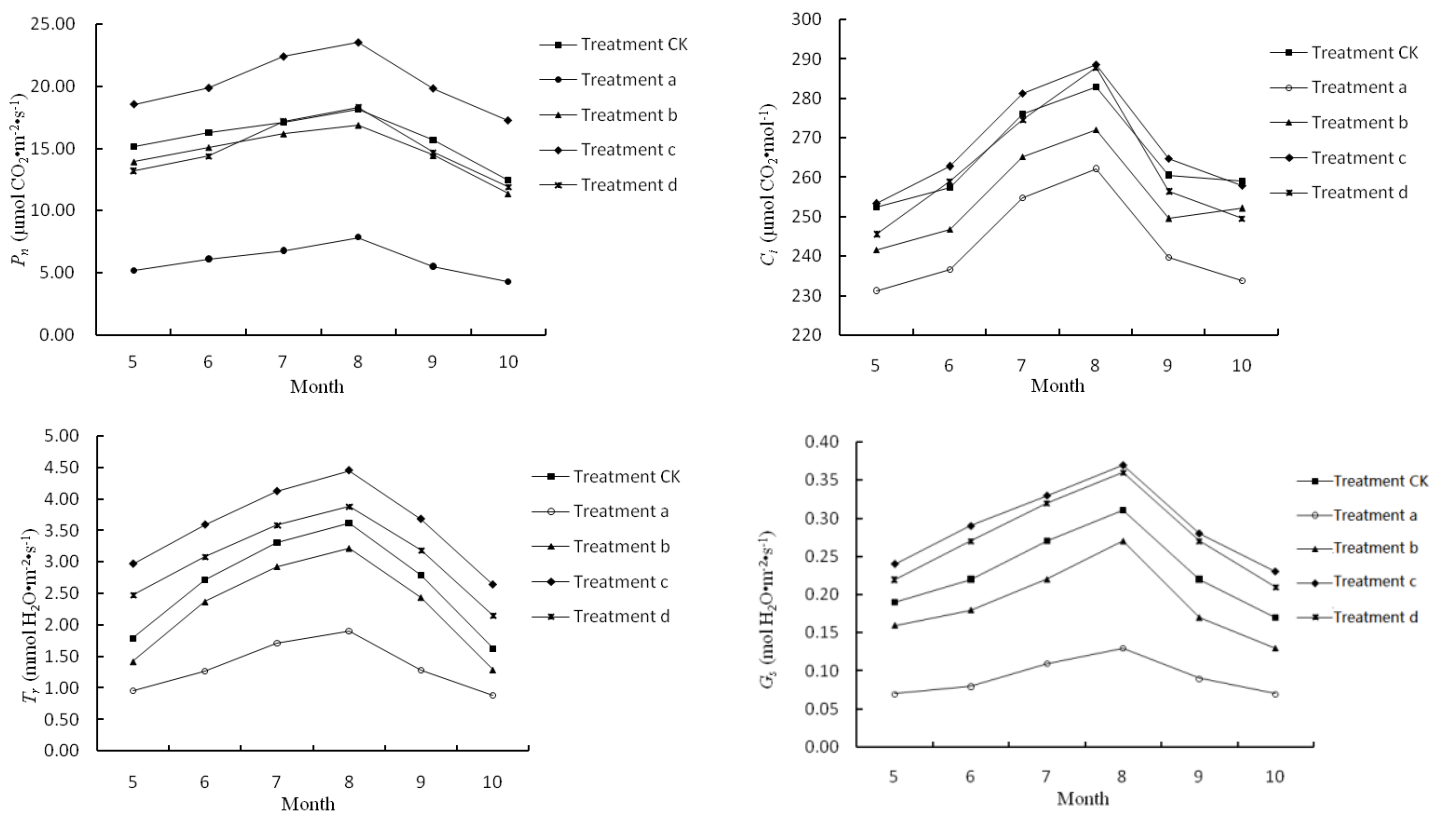

Figure 2. Variations of $P_{n}, G_{s}, C_{i}$ and $T_{r}$ in different growth phases

Photosynthetic capacity of P. sylvestris var. sylvestriformis seedlings under different light conditions

Taking August, where the photosynthetic capacity was the strongest, as an example, the photosynthetic capacity of $P$. sylvestris var. sylvestriformis seedlings under different light conditions was listed in Table 5. $P_{n}$ and $G_{s}$ were treatment LC> LD>CK> LB> LA. Under the condition of treatment LC, $P_{n}$ and $G_{s}$ were $23.52 \mu \mathrm{mol} \mathrm{CO}_{2} \mathrm{~m}^{-2} \mathrm{~s}^{-1}$ and $0.37 \mathrm{~mol} \mathrm{H}_{2} \mathrm{O} \mathrm{m}^{-2} \mathrm{~s}^{-1}$, respectively, which were the highest under each treatment. $P_{n}$ and $G_{s}$ under treatment LA were only $7.85 \mu \mathrm{mol} \mathrm{CO} \mathrm{Cm}^{-2} \mathrm{~s}^{-1}$ and $0.13 \mathrm{~mol} \mathrm{H}_{2} \mathrm{O} \mathrm{m}^{-2} \mathrm{~s}^{-1}$, which were the lowest under all treatments. The difference was significant compared with other treatments $(p<0.05) . T_{r}$ was treatment LC> LD>CK> LB> LA. Under the condition of treatment LC, $T_{r}$ was $4.45 \mathrm{mmol} \mathrm{H}_{2} \mathrm{O} \mathrm{m}^{-2} \mathrm{~s}^{-1}$, which was the highest under each treatment, and the difference from treatment $\mathrm{CK}$ was significant $(p<0.05) . T_{r}$ was $1.90 \mathrm{mmol} \mathrm{H}_{2} \mathrm{O} \mathrm{m}^{-2} \mathrm{~s}^{-1}$ under treatment LA, which was the lowest under all treatments, and the difference was significant compared with other treatments $(p<0.05) . C_{i}$ was treatment $\mathrm{LC}>\mathrm{LD}>\mathrm{CK}>\mathrm{LB}>\mathrm{LA} . C_{i}$ was $288.67 \mu \mathrm{mol} \mathrm{CO}_{2} \mathrm{~mol}^{-1}$ under the condition 
of treatment LC, which was the highest, and Gs was $262.05 \mu \mathrm{mol} \mathrm{CO} \mathrm{Col}^{-1}$ under the condition of treatment LA, which was the lowest in each shading treatment.

Table 5. Effects of different light conditions on photosynthetic capacity of P. sylvestris var. sylvestriformis seedlings

\begin{tabular}{|c|c|c|c|c|}
\hline Tran & $P_{n} / \mu \mathrm{mol} \mathrm{CO}{ }_{2} \mathrm{~m}^{-2} \mathrm{~s}^{-1}$ & $G_{s} / \mathrm{mol} \mathrm{H}_{2} \mathrm{O} \mathrm{m}^{-2} \mathrm{~s}^{-1}$ & $T_{r} / \mathrm{mmol} \mathrm{H}_{2} \mathrm{O} \mathrm{m}^{-2} \mathrm{~s}^{-1}$ & $C_{i} / \mu \mathrm{mol} \mathrm{CO}{ }_{2} \mathrm{~mol}^{-1}$ \\
\hline $\mathrm{CK}$ & $18.16 \pm 0.76 \mathrm{~b}$ & $0.31 \pm 0.04 b c$ & $3.62 \pm 0.16 \mathrm{~b}$ & $283.02 \pm 1.88 \mathrm{~b}$ \\
\hline LA & $7.85 \pm 0.19 \mathrm{~d}$ & $0.13 \pm 0.02 \mathrm{~d}$ & $1.90 \pm 0.16 \mathrm{~d}$ & $262.05 \pm 3.26 \mathrm{~d}$ \\
\hline LB & $16.87 \pm 0.40 \mathrm{c}$ & $0.27 \pm 0.03 \mathrm{c}$ & $3.22 \pm 0.22 \mathrm{c}$ & $272.14 \pm 1.84 \mathrm{c}$ \\
\hline $\mathrm{LC}$ & $23.52 \pm 0.08 \mathrm{a}$ & $0.37 \pm 0.02 \mathrm{a}$ & $4.45 \pm 0.10 \mathrm{a}$ & $288.67 \pm 1.75 \mathrm{a}$ \\
\hline LD & $18.32 \pm 0.39 b$ & $0.36 \pm 0.03 \mathrm{ab}$ & $3.88 \pm 0.09 b$ & $287.88 \pm 0.84 \mathrm{a}$ \\
\hline
\end{tabular}

Note: Lowercase letters in the same column represented significance differences at the $p<0.05$ level

\section{The relationship between photosynthetic rate and main physiological and ecological factors in different growth phases}

According to different growth phases, the order of $P_{n}$ mean value of $P$. sylvestris var. sylvestriformis was peak growth phase $>$ early growth phase $>$ later growth phase (Figure 2). Table 6 showed correlation among photosynthetic and environmental factors. The correlation analysis between main physiological factors $\left(G_{s}, C_{i}, T_{r}\right)$ and ecological factors (Tran, Temp, $R H$ ) and $P_{n}$ showed that the correlation between $P_{n}$ and other physiological and ecological factors such as $G_{s}, C_{i}, T_{r}$, Tran reached a significant level of 0.01 , The correlation between air temperature and air humidity was not significant, and the correlation between factors was complex.

Table 6. Correlation among photosynthetic and environmental factors

\begin{tabular}{c|cccccc}
\hline Factors & $\boldsymbol{P}_{\boldsymbol{n}}$ & $\boldsymbol{C}_{\boldsymbol{i}}$ & $\boldsymbol{G}_{\boldsymbol{s}}$ & $\boldsymbol{T}_{\boldsymbol{r}}$ & Tran & Temp \\
\hline$C_{i}$ & $0.77^{* *}$ & & & & & \\
$G_{s}$ & $0.91^{* *}$ & $0.87^{* *}$ & & & & \\
$T_{r}$ & $0.90^{* *}$ & $0.87^{* *}$ & $0.96^{* *}$ & & & \\
Tran & $0.47^{* *}$ & $0.43^{*}$ & $0.49^{* *}$ & $0.39^{*}$ & & \\
Temp & 0.33 & $0.55^{* *}$ & $0.43^{*}$ & $0.53^{* *}$ & 0.00 & \\
$R H$ & 0.32 & $0.70^{* *}$ & $0.48^{* *}$ & $0.60^{* *}$ & 0.00 & $0.77^{* *}$ \\
\hline
\end{tabular}

Note: $*$ represents significant level at $0.05 ; * *$ represents significant level at 0.01

In order to further analyze the relationship between $P_{n}$ and main physiological and ecological factors at different growth phases, path analysis was conducted on each factor $(\mathrm{X})$ and $P_{n}(\mathrm{Y})$. The weight of each factor influencing $P_{n}$ was analyzed by path analysis. The results were shown in Table 7. The main factors that had great influence on $P_{n}$ in different growth phases were different. In the early growth phase, physiological factors $C_{i}$, ecological factors Tran and Temp jointly affected the changes of $P_{n}$, the most direct effect on $P_{n}$ was $C_{i}$. Tran and Temp had a greater indirect effect on $P_{n}$ through $C_{i}$. In the peak growth phase, $T_{r}, R H$ and Tran had a greater direct positive effect on $P_{n}$. $C_{i}$ and $G_{s}$ had a direct negative effect on $P_{n}$, Tr was the physiological factor that had the greatest 
effect on $P_{n}$, Tran and $R H$ were the ecological factors that had the greatest effect on $P_{n}$. In the late growth phase, $T_{r}$ and $C_{i}$ had a large direct positive effect on $P_{n}, G_{s}$, Tran and Temp had a direct negative effect on $P_{n}$.

Table 7. Path analysis between the factors and Pn in different growth phases

\begin{tabular}{c|c|c|c|c|c|c|c|c|c}
\hline $\begin{array}{c}\text { Growth } \\
\text { phases }\end{array}$ & Factors & $\begin{array}{c}\text { Direct } \\
\text { path }\end{array}$ & $\begin{array}{c}\text { Indirect } \\
\text { path }\end{array}$ & $\begin{array}{c}\text { Through } \\
\boldsymbol{C}_{\boldsymbol{i}}\end{array}$ & $\begin{array}{c}\text { Through } \\
\boldsymbol{G}_{\boldsymbol{s}}\end{array}$ & $\begin{array}{c}\text { Through } \\
\boldsymbol{T}_{\boldsymbol{r}}\end{array}$ & $\begin{array}{c}\text { Through } \\
\text { Tran }\end{array}$ & $\begin{array}{c}\text { Through } \\
\text { Temp }\end{array}$ & $\begin{array}{c}\text { Through } \\
\boldsymbol{R H}\end{array}$ \\
\hline \multirow{2}{*}{$\begin{array}{c}\text { Early } \\
\text { growth }\end{array}$} & $C_{i}$ & 1.214 & -0.335 & - & - & - & --0.193 & -0.141 & - \\
phase & Tran & -0.290 & 0.808 & 0.808 & - & - & - & 0.000 & - \\
\hline & Temp & -0.356 & 0.482 & 0.482 & -- & - & 0.000 & - & - \\
\hline \multirow{4}{*}{$\begin{array}{c}\text { Peak } \\
\text { growth }\end{array}$} & $C_{i}$ & -0.439 & 1.322 & - & -0.645 & 1.887 & 0.047 & - & 0.034 \\
phase & $G_{s}$ & -0.675 & 1.613 & -0.419 & - & 1.970 & 0.043 & - & 0.019 \\
& $T_{r}$ & 2.004 & 1.613 & -0.413 & -0.664 & - & 0.040 & - & 0.014 \\
& $R H$ & 0.086 & 0.013 & -0.171 & -0.150 & 0.334 & 0.000 & - & - \\
& Tran & 0.075 & 0.414 & -0.276 & -0.385 & 1.075 & - & - & 0.000 \\
\hline \multirow{3}{*}{$\begin{array}{c}\text { Later } \\
\text { growth }\end{array}$} & $C_{i}$ & 1.082 & -0.158 & - & -1.640 & 1.620 & -0.073 & -0.065 & - \\
& $G_{s}$ & -1.781 & 2.757 & 0.996 & - & 1.950 & -0.056 & -0.134 & - \\
& $T_{r}$ & 2.041 & -1.119 & 0.859 & -1.701 & - & -0.039 & -0.237 & - \\
& Tran & -0.104 & 0.581 & 0.760 & -0.951 & 0.772 & - & 0.000 & - \\
& Temp & -0.452 & 0.699 & 0.156 & -0.529 & 1.072 & 0.000 & - & - \\
\hline
\end{tabular}

\section{Discussion}

Plant growth is inseparable from sunlight. Light can directly promote the growth and division of plant cells, promote the differentiation of plant tissues and organs, and affect plant growth and development speed (Huang et al., 2020). The results showed that when the light transmittance was $10 \%$, the growth of plant height, ground diameter, and leaf length in the growing season was the lowest in all treatments. The average plant height increment was only $4.76 \mathrm{~cm}$, the average ground diameter increment was only $0.45 \mathrm{~mm}$, and the average leaf length increment was only $1.71 \mathrm{~cm}$. In a different light environment, the $P$. sylvestris var. sylvestriformis seedlings showed different growth characteristics. Within a certain range of light intensity, the growth of plants always increased with the increase of light intensity (Welander and Ottosson, 1998; Wen et al., 1999). Some studies also considered that plants grew best at moderate light intensity (Valladares et al., 2000). The result of this experiment was consistent with that. According to the statistical results of phenotypic data, when the light transmittance was $40 \%$, the growth of plant height, ground diameter, and leaf length in the growing season were the highest in all treatments. The average plant height increment was $10.76 \mathrm{~cm}$, the average ground diameter increment was $1.43 \mathrm{~mm}$, and the average leaf length increment was $4.18 \mathrm{~cm}$. Growth indicators such as seedling height growth and ground stem growth under the light condition of $40 \%$ light transmittance were higher than other treatments, indicating that the seedlings of $P$. sylvestris var. sylvestriformis can promote plant growth under moderate shading treatment. It is consistent with the research results of Clerodendrum japonicum seedlings (Huang et al., 2020).

The growth of plant height, leaf length, and ground diameter were three important phenotypic indexes of $P$. sylvestris var. sylvestriformis seedlings, combined with 
photosynthetic characteristics as four indexes, whose differences could comprehensively reflect the effects of different shading treatments. Excessive shading would restrict the photosynthesis of $P$. sylvestris var. sylvestriformis seedlings. Choosing suitable light conditions was more conducive to the growth of seedlings. Some scholars have confirmed that heavy shading is not suitable for seedling growth (Jiang et al., 2017). Therefore, understanding the response of seedlings to different light environments is of great practical significance for studying the succession and ecological restoration of $P$. sylvestris var. Sylvestriformis community.

Photosynthesis is the basis of plant material production. It is not only affected by environmental factors, but also closely related to its own growth and development and physiological and ecological characteristics. The continuous changes in environmental temperature and humidity brought about by the growth of plants and the changing of seasons will inevitably cause the photosynthetic characteristics of plants to change with the changing of seasons and growth phases. Under treatment $\mathrm{CK}$, the light transmittance of $20 \%$, the light transmittance of $40 \%$, and light transmittance of $60 \%$, plant height of $P$. sylvestris var. sylvestriformis grew rapidly in the period of June-July, and the seedlings could make good use of light energy. When the light transmittance was $10 \%$, the plant height grew slower than that of other treatments in the period of June-July, and the seedlings could not get enough light energy. However, in the period of July-August, when other treatments showed strong light suppression, the seedlings had enough light energy for photosynthesis under $10 \%$ light transmittance.

The net photosynthetic rate $\left(P_{n}\right)$ is the result of the comprehensive effect of plant growth and the external environment, and its size restricts the speed of plant growth (Shang et al., 2020). The higher the $P_{n}$, the stronger the adaptability of the plant and the more favorable it is for growth. The intercellular $\mathrm{CO}_{2}$ concentration $\left(C_{i}\right)$ is an important factor affecting plant photosynthesis, and stomata is an important channel that directly affects the exchange of water vapor and $\mathrm{CO}_{2}$. Excessive closure of stomata will have certain effect on the transpiration of plants and cause certain effects (Yue et al., 2020). $P_{n}, C_{i}$ and the transpiration rate $\left(T_{r}\right)$ were $\mathrm{LC}>\mathrm{LD}>\mathrm{Ck}>\mathrm{LB}>\mathrm{LA}, \mathrm{LC}$ treatment was higher than other treatments, and LA treatment was the lowest. It showed that moderate shading could increase the $P_{n}, C_{i}$, and $T_{r}$ of plants. When excessive shading, the net photosynthetic rate of $P$. sylvestris var. sylvestriformis decreased sharply. In addition, the intercellular $\mathrm{CO}_{2}$ concentration was low, and the degree of stomata opening restricted the transportation of $\mathrm{CO}_{2}$, the transpiration rate also decreased (Yue et al., 2020).

In the early growth phase, the internal structure and function development of the leaves were not perfect, the stomata of the leaves were partially closed, $G_{s}$ was still relatively low. $P_{n}$ of the leaves changed with the change of $C_{i}$. This was a regular reflection of the relationship between the two. At this time, $P_{n}$ was low. In the peak growth phase, the color of leaves gradually changed from light green to thick green, and the internal structure and function of leaves gradually developed and perfected $G_{s}, T_{r}$ and $C_{i}$ were higher. The resistance of water and $\mathrm{CO}_{2}$ entering and exiting the stomata and photosynthesis was small, which was conducive to the analysis of photosynthesis (Chen et al., 2015). It was worth noting that path analysis showed that Tran and $R H$ were important ecological factors affecting photosynthesis at this stage. In later growth phase, the growth of $P$. sylvestris var. sylvestriformis was slow or even stagnant, and $G_{s}$ was still an important physiological factor affecting photosynthesis. 


\section{Conclusion}

There were some differences in the growth of $P$. sylvestris var. sylvestriformis seedlings under different shading treatments. Plant height, ground diameter, and leaf length were the most direct reflection of seedling growth and seedling quality. $P$. sylvestris var. sylvestriformis showed a good growth trend under the shading condition of $40 \%$ light transmittance. Under low light intensity, the light was the limiting factor for seedling growth. Under the condition of insufficient light resources, the growth of plant height, ground diameter, and leaf length in the growing season were all inhibited by a light factor, showing the smallest with significant change, whose growth was inhibited.

Excessive shading or full light was not conducive to the growth of $P$. sylvestris var. sylvestriformis seedlings. Excessive shading inhibited the normal progress of photosynthesis and reduced the content of photosynthetic products. under full light conditions, although photosynthesis was the strongest, photoinhibition would appear, Inhibiting the normal progress of photosynthesis. The research results showed that $P_{n}, C_{i}$, and $T_{r}$ were the highest when light transmittance was $40 \%$.

In conclusion, through the study on the growth status of $P$. sylvestris var. sylvestriformis under different light conditions, it was found that moderate light environment could promote the growth of $P$. sylvestris var. sylvestriformis seedlings. The phenotypic index and photosynthetic physiological and ecological indicators were the highest when the light transmittance was $40 \%$. It was the best light condition for the growth and ecological adaptation of $P$. sylvestris var. sylvestriformis seedlings. Through the observation of photosynthetic characteristics in different growth phases, it was found that the growth of $P$. sylvestris var. sylvestriformis and their photosynthetic changes overlapped. In different growth phases, the physiological and ecological factors affecting the photosynthesis of $P$. sylvestris var. sylvestriformis were different. In the early growth phase from May to June, the photosynthetic rate of $P$. sylvestris var. sylvestriformis increased rapidly, $C_{i}$ was the decisive factor affecting the photosynthetic rate of $P$. sylvestris var. sylvestriformis in this phase, and the light transmittance and air relative temperature were the important environmental factors affecting the photosynthetic rate. In the peak growth phase from July to August, Tran and $R H$ were the important ecological factors affecting photosynthesis in this phase. In the later growth phase from September to October, the photosynthetic rate gradually decreased. Therefore, in the peak and later growth phases, shade conditions could be used to properly adjust the air temperature and humidity to achieve the optimum temperature and humidity range for photosynthesis, increase the photosynthetic rate of the leaves, promote and extend the growth season of P. sylvestris var. sylvestriformis.

$P$. sylvestris var. sylvestriformis is unique and rare woody plants in Changbai Mountain of China. The limitation of the number of experimental materials has caused many restrictions on the experiment. In the future, under the premise of limited experimental materials, it is necessary to explore the light response of $P$. sylvestris var. sylvestriformis from the perspectives of morphology, anatomy and gene expression. In addition, it is more convincing to analyze the specific mechanism of the influence of light environment on P. sylvestris var. sylvestriformis from the molecular level.

Acknowledgements. This research was financially supported by the Scientific and Technological Development Project of Jilin Province, China (Grant No. 20180101017JC) (Grant No. 20200201188JC), and the central government guides the local science and technology development fund project Jilin Province basic research special project (Grant No. 202002077JC). 


\section{REFERENCES}

[1] Bazzaz, F. A. (1996): Plants in changing environments: linking physiological, population, and community ecology. - Cambridge University Press, Britain.

[2] Bu, J., Zou, C. J., Xu, W. D. (1995): Study on the relationship between growth and development and ecological conditions of Pinus sylvestriformis. - Journal of Shenyang Teachers College (Natural Science) 3: 47-51.

[3] Chen, Y., Yu, J., Huang, B. (2015): Effects of elevated $\mathrm{CO}_{2}$ concentration on water relations and photosynthetic responses to drought stress and recovery during rewatering in Tall Fescue. - J Am Soc Hortic Sic 140: 19-26.

[4] Chen, X. L., Li, L., Huang, Y. S. (2017): The growth laws of Pinus sylvestris var. Sylvestriformis (Takenouchi) Cheng et C. D. Chu. - Shaanxi Forestry Science and Technology 6: 35-37.

[5] Duan, B. L., Lü, Y. W., Yin, C. Y., Li, C. (2005): Morphological and physiological plasticity of woody plant in response to high light and low light. - Chinese Journal of Applied and Environmental Biology 11(2): 238-245.

[6] Hu, Y. M., Xu, W. D., Zheng, Y. R. (1996): Spatial distribution pattern of natural Pinus sylvestriformis population with same age. - Journal of Applied Ecology 7(02): 113-116.

[7] Huang, W. Y., Feng, Z. J. (2020): Effect of light intensity on the growth and photosynthetic characteristics of Clerodendrum japonicum. - Forestry and Environmental Science 36(04): 96-101.

[8] Jiang, R. F., Liu, Y. H. (2017): Effects of light intensity on photosynthesis and growth characteristics of Davidia involucrata seedlings. - Ecological Science 36(05): 114-120.

[9] Jin, H., Zhao, Y., Zhao, W. et al. (2015): Natural population status and endangered mechanism of Pinus sylvestriformis in Changbai Mountain. - Journal of Beihua University (Natural Science) 16(5): 661-665.

[10] Kim, J. H., Lee, H. J., Park, C. M. (2017): HOS1 acts as a key modulator of hypocotyl photomorphogenesis. - Plant Signaling \& Behavior 12(5): e1315497.

[11] Liu, J. F., Yang, W. J., Jiang, Z. P., Guo, Q. (2011): Effects of shading on photosynthetic characteristics and chlorophyll fluorescence parameters in leaves of the endangered plant Thuja sutchuenensis. - Acta Ecologica Sinica 31(20): 5999-6004.

[12] Rozendaal, D. M. A., Hurtado, V. H., Poorter, L. (2006): Plasticity in leaf traits of 38 tropical tree species in response to light: relationships with light demand and adult stature. - Functional Ecology 20(2): 207-216.

[13] Shang, S. J., Wang, Y. J., Wang, N., Yang, J. L., Xu, S., He, X. Y., Chen, W. (2020): Effects of light intensity on physiological and growth characteristics of Paeonia suffruticosa var. papaveracea. - Chinese Journal of Ecology 39(9): 2963-2973.

[14] Smith, T., Huston, M. (1989): Atheory of the spatial and temporal dynamics of plant communities. - Vegetatio 83(1/2): 49-69.

[15] Valladares, F., Wright, S. J., Lasso, E., Kitajima, K., Pearcy, R. W. (2000): Plastic phenotypic response to light of 16 congeneric shrubs from a panamanian rainforest. Ecology 81(7): 1925-1936.

[16] Wang, J. M. (2008): Brief analysis of Korean pine plantation translucent tending. - Journal of Heilongjiang Ecological Engineering Vocational College 21(2): 21-22.

[17] Welander, N. T., Ottosson, B. (1998): The influence of shading on growth and morphology in seedlings of Quercus robur L. and Fagus sylvatica L. - Forest Ecology and Management 107: 117-126.

[18] Wen, D. Z., Kong, G. H., Lin, Z. F., Ye, W. H. (1999): A comparative study on the growth responses to light intensity in seedlings of four subtropical tree species. - Journal of Tropical and Subtropical Botany 7(2): 125-132.

[19] Yin, H., Zhao, Y., Jin, H., Liu, L. J., Zhang, D. W., Bing, G. P., Wang, C., Meng, Q. J. (2017): The experiment of preventing Thuja koraiensis cutting seedling frost heaving 
damage in Changbai mountain. - Journal of Jilin Forestry Science and Technology 46(3): $1-2$.

[20] Yue, G. F., Han, Z. Q., Xue, Z. W. et al. (2020): The effect of different shades on the flowering period and photosynthetic characteristics of peony. - Jiangsu Agricultural Sciences 48(17): 166-170.

[21] Zhao, S. J., Yan, K. S., Zhang, H. J. et al. (2002): Investigation report on introduction of Pinus sylvestris. - Hebei Forestry Science and Technology 5: 13-14.

[22] Zhao, Y., Jin, H., Yin, H., et al. (2017): Effects of different exogenous hormones on Seed Germination Ability of Pinus sylvestriformis. - Journal of Beihua University (Natural Science) 6: 722-726. 